\title{
HIV disclosure to sexual partner and associated factors among women attending ART clinic at Mekelle hospital, Northern Ethiopia
}

\author{
Mussie Alemayehu ${ }^{1 *}$, Alemseged Aregay ${ }^{2 \dagger}$, Abrhet Kalayu $^{3 \dagger}$ and Henock Yebyo ${ }^{1+}$
}

\begin{abstract}
Background: Disclosure of HIV positive status has two sets of contrary effects. It may motivate partner for Voluntary Counseling and Testing; on the other hand, it may cause blame, discrimination, depression and loss of economic support. Consequently, HIV positive status disclosure among women has become one of the major concerns that should be addressed in HIV prevention and control activities. This study aimed at assessing the magnitude and factors related to HIV positive status disclosure to sexual partners among HIV positive women.

Methods: A cross sectional study was conducted in Mekelle hospital from July 10-26, 2013 to collect data from 315 HIV positive women using a systematic random sampling. Descriptive and multiple logistic regression analyses were performed using SPSS 20 for windows to estimate indicators and effect sizes of the predictors on HIV disclosure status to partners.

Results: The proportion of HIV disclosure status to their partner was 63.8\%. Women who knew the HIV status of their sexual partner and those who got pretest counseling had a positive association with HIV disclosure with AOR of 16.9 (95\% Cl: 8.11, 35.21) and AOR of $2.8(95 \% \mathrm{Cl}: 1.83,4.28)$. Mothers with two years or beyond, since they knew their HIV status had more odds ( $\mathrm{AOR}=3.2,95 \% \mathrm{Cl}: 1.7,6.29)$ to disclose their HIV status to their partner. Mothers who had seen people with HIV positive who disclose their HIV status to the community (AOR $=2.1,95 \% \mathrm{Cl}: 1.08$, 4.01) and those who had a discussion prior to HIV testing (AOR $=4.87,95 \% \mathrm{Cl}: 2.45,9.71)$ were more likely to disclose their HIV status than their counterparts.

Conclusions: The rate of HIV disclosure to their partner was low. Knowledge of HIV status of partner, receiving pretest counseling, longer time since the HIV testing, know people who disclose their status to the community and having discussion prior to HIV testing could influence disclosure of HIV status of mothers to their partners.
\end{abstract}

Keywords: Disclosure, HIV, Women, Mekelle, Tigray, Ethiopia

\section{Background}

The Human Immunodeficiency Virus (HIV) epidemic continues to be a major public health problem worldwide. At the end of 2010, there were an estimated 34 million people living with HIV/AIDS. Sub-Saharan Africa (SSA) bears an inordinate share of the global HIV burden accounting for $68 \%$ of all patients living with HIV/AIDS (PLWHA); of which, 59\% of them were women [1,2]. Though the HIV prevalence in Ethiopia

\footnotetext{
* Correspondence: mossalex75@gmail.com

${ }^{\dagger}$ Equal contributors

'Department of Public Health, Mekelle University College of Health Sciences, Mekelle, Ethiopia

Full list of author information is available at the end of the article
}

is lower than many SSA countries, its epidemic led it to be one of the countries with huge magnitude HIVinfected people worldwide.

According to the 2010 single point estimate, the estimated adult HIV/AIDS prevalence in Ethiopia was 2.4\% [3]. A larger proportion of these are under treatment. A number of factors determine for the success of the treatment. HIV positive status disclosure among women has become one of the major concerns that should be addressed in HIV prevention \& control activities which is one of the factors that determine the success of HIV/ AIDS related programs [4]. Moreover, it may affect the rate of transmission of the virus to their sexual partners 
[5,6]. Early disclosure of HIV positive status of women to sexual partner is crucial and helpful for treatment adherence, HIV transmission reduction, PMTCT interventions, partner testing and acceptance of referrals for HIV-related care, treatment and support.

Nevertheless, disclosure of HIV positive status has two sets of contrary effects. It may motivate partner for Voluntary Counseling and Testing (VCT), reduce risk behaviors, and increase acquisition of support and adherence to ART $[7,8]$. On the other hand, it may cause blame, discrimination, abandonment, depression and loss of economic support and disruption of family relationship. For the fear of these risks, patients may not disclose their HIV positive status $[9,10]$ which, in turn, may have a negative effect on women's treatment outcome of HIV/AIDS care. However, evidences are scarce regarding to the HIV discloses and factors determining HIV disclose to their partners.

This study aimed to assess the level of HIV disclosure and factors related to the disclosure among women living with HIV in Mekelle hospital, northern Ethiopia.

\section{Methods}

An institutional based cross-sectional study was conducted in Mekelle hospital from July 10-26,2013. The total population of the area is 233,000 , with 119,800 females and the health service coverage of Mekelle city was $90 \%$ [11]. Tigray is the dominant ethnic group in Mekelle. All HIV positive women aged 18 years or above who have been registered and getting clinical service at the ART clinic in Mekelle hospital were considered as source population. Clients who were critically ill during the data collection period were excluded from the study.

To determine the sample size, a single population proportion formula with a proportion of disclosure in Mettu and Gore town was 69\% [5], a confidence level of 95\%, and a 5\% degree of precision were used. With assumption of $10 \%$ non response rate, the total sample size computed was 315 .

Systematic random sampling was used to select the study subjects. There were a total of 2,218 female patients who follow chronic ART care in the hospital. Based on the sample fraction, women were selected at equal interval using systematic random sampling. Those who didn't fulfil the inclusion criteria were excluded and the next women fulfilling the criteria were included. However, women who refused to participate were excluded from the study without replacement.

Structured and pre-tested questionnaire, guided by the interviewer, was used to collect the information. It was first prepared in English and then translated into the local language (Tigrigna) and then translated back to English to check for consistency of the questions.
Information collected included socio demographic and economic characteristics, individual and partner factor, health and health related factors and disclosure of HIV status. The questionnaire was adapted from different literatures and considering the local situation of the study subjects $[5,12,13]$. Four diploma clinical nurses who can speak the local languages were employed in the data collection process. Two BSc nurses were posted for supervision. Training was given to the data collectors and supervisors for two consecutive days on the purpose of the study, the contents of the questionnaire, particularly on issues related to the confidentiality of the responses and the rights of respondents. One week prior to the data collection, the questionnaire was pretested at Quiha district in 16 of women.

The data collected was entered into and analyzed using SPSS 20 for windows (SPSS Inc. Version 20., Chicago, Illinois). Exploratory data was run to check for missing values, outliers and expected values of the categories for regression. Descriptive and multiple logistic regression was used to estimate the respective indicators, and effects of factors on the HIV disclosure of the mothers to their partners. Collinearity among independent factors was checked using VIF. The sample effect size was estimated using $\mathrm{OR}$ and the parameters were estimated using 95\% confidence interval of the OR. For all the analyses, P-value less than 0.2 was considered statistically significant.

The study was approved by the ethical committee of Mekelle University, College of health science research and community service committee. Formal letter of permission was obtained from Mekelle University and Tigray Regional Health Bureau. A letter was also obtained from the director of Mekelle hospital that assured to continue the study. Verbal consent was obtained from the study respondents individually. The right of the respondent to withdraw from the interview or not to participate at all was assured.

\section{Results}

\section{Socio demographic and economic characteristics}

A total of 315 HIV positive women had participated in the study with a response rate of $100 \%$. The majority of the respondents were urban 259 (82\%) and Orthodox Christianity followers 276 (84.8\%). One hundred thirty nine $(44.1 \%)$ and $220(69.8 \%)$ of the respondents were married and literate, respectively. Pertaining to the educational status of their partner, 97 (30.8\%) attended college or university. The overall respondents age ranges from 20 to 65 with mean of age $34.9( \pm 8.1)$ years (Table 1).

Health and health care related factors of the respondents The length of time since the mothers knew their HIV status differed. In nearly $60 \%$ of them, it has been 2 years 
Table 1 Socio-demographic characteristics of the women on ART at Mekelle Hospital, Northern Ethiopia

\begin{tabular}{|c|c|c|}
\hline Variable & Number & Percent \\
\hline \multicolumn{3}{|l|}{ Residence } \\
\hline Urban & 259 & 82.2 \\
\hline Rural & 56 & 17.8 \\
\hline \multicolumn{3}{|l|}{ Ethnicity } \\
\hline Tigray & 293 & 93 \\
\hline Amhara & 22 & 7 \\
\hline \multicolumn{3}{|l|}{ Age } \\
\hline $20-24$ & 22 & 7 \\
\hline $25-29$ & 57 & 18.1 \\
\hline $30-34$ & 76 & 24.1 \\
\hline $35-39$ & 68 & 21.6 \\
\hline $40-44$ & 53 & 16.8 \\
\hline$>=45$ & 39 & 12.4 \\
\hline \multicolumn{3}{|l|}{ Occupation } \\
\hline Daily worker & 35 & 11 \\
\hline Governmental employee & 57 & 18.1 \\
\hline NGO employee & 50 & 15.9 \\
\hline Housewife & 102 & 32.4 \\
\hline Merchant & 15 & 4.8 \\
\hline Farmer & 56 & 17.8 \\
\hline \multicolumn{3}{|l|}{ Marital status } \\
\hline Single & 25 & 7.9 \\
\hline Married & 139 & 44.1 \\
\hline Divorced & 72 & 22.9 \\
\hline Separated & 10 & 3.2 \\
\hline Widowed & 69 & 21.9 \\
\hline \multicolumn{3}{|l|}{ Religion } \\
\hline Orthodox & 267 & 84.8 \\
\hline Muslim & 36 & 11.4 \\
\hline Others* & 12 & 3.8 \\
\hline \multicolumn{3}{|c|}{ Educational status of the respondents } \\
\hline Illiterate & 95 & 30.2 \\
\hline Write and read & 16 & 5.1 \\
\hline Primary school (1-8) & 101 & 32.1 \\
\hline Secondary school (9-12) & 41 & 13 \\
\hline College or university level & 62 & 19.7 \\
\hline \multicolumn{3}{|c|}{ Educational status of their partner } \\
\hline Illiterate & 37 & 11.7 \\
\hline Write and read & 36 & 11.4 \\
\hline Primary school (1-8) & 79 & 25.1 \\
\hline Secondary school (9-12) & 66 & 21.0 \\
\hline College or university level & 97 & 30.8 \\
\hline
\end{tabular}

*Others (catholic and protestant). or beyond, since they knew their HIV status. Five out of ten mothers were tested their HIV status in VCT while the rest were tested in different situations. In 169 (53.5\%) of the mothers, illness caused them to get tested for an HIV test. Sixty percent of the mothers didn't have a discussion about HIV test with their partners. During HIV testing, only 28 (11.5\%) came with their partners and were counseled together. The rest of the women came alone.

More than half, 175 (55.6\%), of the women had been staying in ART and/or Pre-ART for 2 years or over. Nearly $84 \%$ of the women were under the ART during the study period. With regard to their perception, 253 (80.3\%) thought ART initiation is important for disclosure of HIV status. One hundred fifty seven $(85 \%)$ of the HIV positive women were living in the same house with their current sexual partner for at least one year (Table 2).

\section{Disclosure status, sexual experience and individual factors of the respondents}

Nearly $64 \%$ of the HIV positive women disclosed their HIV status to their partners. Of those, 169 (84\%) of the respondents disclosed their status to their usual partner, whereas $32(16 \%)$ to their causal partner. With regard to intention, $66.7 \%$ of the undisclosed women didn't have an intention to disclose their HIV status to their partner. Majority of the women (85\%) disclosed their status after ART initiation. The main reasons mentioned by the women to disclose their status were the influence in due by another HIV positive individual (31.8\%) and seeking support from their partner (26.4\%). Whereas, on the contrary, the main reason for not disclosing their status was fear of separation (22.8\%). Over half of the women (53\%) haven't recognized any person who discloses his/ her HIV status to the community.

Pertaining to their sexual practice, $55.2 \%$ of the women practiced sexual intercourse in the last six months of the interview. Of these, $64.6 \%$ had always used condoms (Table 3 ).

\section{Factors associated with HIV disclosure}

The result of the multivariate analyses showed that women who knew their partner's HIV status were more likely to disclose their own (AOR $=16.9$; 95\% CI: 8.11, 35.21). Pretest counseling was also positively associated with HIV disclosure of the women as compared to their counterparts $(\mathrm{AOR}=2.8,95 \% \mathrm{CI}: 1.83,4.28)$. Women who knew their HIV status for longer than 2 years had 3 times higher odds of disclosing their HIV status to their partner than women with relatively shorter $(\mathrm{AOR}=3.2$, $95 \%$ CI $(1.7,6.29)$. The result substantiates the help of model HIV positive individuals in disclosing HIV status. Women who had seen an HIV positive person disclosing his/her status to the community had 2 times higher odds 
Table 2 Health and health care related factors of respondents at Mekelle Hospital, Northern Ethiopia

\begin{tabular}{|c|c|c|}
\hline Variables & Number & Percent \\
\hline \multicolumn{3}{|l|}{ Time to know your HIV sero positive } \\
\hline$<=2$ years & 124 & 39.4 \\
\hline$>2$ years & 191 & 60.6 \\
\hline \multicolumn{3}{|l|}{ Place of test for HIV } \\
\hline ANC & 78 & 24.8 \\
\hline Delivery & 24 & 7.6 \\
\hline VCT & 157 & 49.8 \\
\hline Providing is initiating counseling and testing & 56 & 17.8 \\
\hline \multicolumn{3}{|l|}{ Discussion before test with partner } \\
\hline Yes & 99 & 31.4 \\
\hline No & 216 & 68.6 \\
\hline \multicolumn{3}{|l|}{ Relationship before test with partner } \\
\hline Smooth & 218 & 69.2 \\
\hline Disagreement & 97 & 30.8 \\
\hline \multicolumn{3}{|l|}{ Initiating factor to test for HIV } \\
\hline Becoming sick & 169 & 53.5 \\
\hline Others* & 146 & 46.5 \\
\hline \multicolumn{3}{|l|}{ Duration of follow up in ART or pre ART service } \\
\hline$<=2$ years & 140 & 44.4 \\
\hline$>2$ years & 175 & 55.6 \\
\hline \multicolumn{3}{|c|}{ History of Hospital admission in the last 12 months } \\
\hline Yes & 60 & 19.0 \\
\hline No & 255 & 81.0 \\
\hline \multicolumn{3}{|l|}{ Current category of respondents } \\
\hline Pre-ART Rx & 45 & 14.3 \\
\hline ART Rx & 270 & 85.7 \\
\hline \multicolumn{3}{|l|}{ Initiating ART is important for disclosure } \\
\hline Yes & 253 & 80.3 \\
\hline No & 62 & 19.7 \\
\hline \multicolumn{3}{|c|}{ Regular sexual partner in the last 12 months $(n=315)$} \\
\hline No & 130 & 41.3 \\
\hline Yes & 185 & 57.7 \\
\hline \multicolumn{3}{|c|}{ Live in the same house with regular sexual partner $(n=185)$} \\
\hline Yes & 157 & 85 \\
\hline No & 28 & 15 \\
\hline \multicolumn{3}{|c|}{ Numbers of years lived with sexual partner $(n=157)$} \\
\hline$<=1$ year & 23 & 14.6 \\
\hline$>1$ year & 134 & 85.4 \\
\hline
\end{tabular}

*Friends, family and health professionals.

to disclose their HIV status (AOR $=2.1,95 \% \mathrm{CI}: 1.08,4.01)$. Discussion with their partners on the need of HIV testing was associated with higher odds of disclosing women's HIV status to their partner (AOR $=4.87,95 \%$ CI: 2.45 , 9.71) (Table 4).

\section{Discussion}

The study assessed the magnitude and factors affecting disclosure of HIV positive status to their sexual partners in Mekelle hospital. The overall disclosure rate of HIV status of women to their sexual partner was $63.8 \%$. On the multiple logistic regression, knowledge of sexual partner's HIV status, receiving pretest counseling, duration since HIV testing, knowing people who disclose their status to the community and having a discussion with their partners prior to HIV testing were the predictor of HIV disclosure.

The entry point for an effective HIV/AIDS care and treatment, including adherence to the ART drug and having a successful PMTCT intervention is disclosure of HIV status to a sexual partner. However, in most of the developing countries, including Ethiopia, women are economically dependent on men, and this might have an effect in expressing their status freely to their sexual partner. Besides, in this study one third women had no discussion with their partner prior to the HIV test and this might have an effect of having a low disclosure rate. Consistent findings were also found in studies conducted in Mettu and Gore town (69\%) [5]. However, it is less than other studies conducted in the USA (82\%), Kemissie Health Center (93.1\%), Hawassa referral hospital (85.7\%), California (100\%) and Jimma (85\%) [7,12-15].

Being a member of HIV/AIDS association could provide women with information regarding the merit of disclosure as well as for sharing and discussing their problems freely with other individuals so as to help them in acquiring possible solution. This in turn might have an effect in disclosure of HIV status. However, this study report that a large number (71.7\%) women were not a member as compared with neighbored countries like Republic of Tanzania (22\%) and Rwanda (50.9\%) [16,17].

It is obvious that, as the patients stay longer duration in HIV care services, they are informed about the benefits of HIV/AIDS care treatment, including disclosure, experience sharing with others and got ongoing counseling. These services may encourage the women to disclose their HIV status to their partner. Similar findings were shown in different studies [17-19] - including this study in which disclosure to sexual partners increased from $18 \%$ within one month of diagnosis to $42 \%$ to six months.

Women had different reasons not to disclose their HIV status or not. Moreover, this study revealed that getting support from a sexual partner, partners help to get medical and ART care and the intention to decrease HIV transmission of HIV/AIDS to their partner were the main reason mentioned by the women to disclose their HIV status. On the other hand, fear of abandonment, having not enough time to discuss with their partner, fear of physical abuse, stigma and discrimination 
Table 3 Sexual experiences and factors related to HIV disclosure among women at Mekelle Hospital, Northern Ethiopia

\begin{tabular}{|c|c|c|}
\hline Variables & Number & Percen \\
\hline \multicolumn{3}{|l|}{$\begin{array}{l}\text { Period of disclosure to their partner after } \\
\text { testing HIV }(n=201)\end{array}$} \\
\hline Immediately & 26 & 13 \\
\hline$<1$ months & 36 & 18 \\
\hline $1-6$ months & 52 & 26 \\
\hline$>6$ months & 87 & 43 \\
\hline \multicolumn{3}{|l|}{ Type of partner for disclosure $(n=201)$} \\
\hline Steady sexual partner & 169 & 84.0 \\
\hline Causal sexual partners & 32 & 16.0 \\
\hline \multicolumn{3}{|l|}{$\begin{array}{l}\text { Time of disclosure to sexual } \\
\text { partner }(n=201)\end{array}$} \\
\hline Before starting ART & 30 & 15 \\
\hline After initiating ART & 171 & 85 \\
\hline \multicolumn{3}{|l|}{ Reasons for decide to discloser $(n=201)$} \\
\hline Peer support & 10 & 5.0 \\
\hline Mass media & 55 & 27.4 \\
\hline HIV positive individuals & 64 & 31.8 \\
\hline Self & 48 & 23.9 \\
\hline Partner & 24 & 11.9 \\
\hline \multicolumn{3}{|l|}{ Reason for their disclosure $(n=201)$} \\
\hline To get support from their sexual partner & 53 & 26.4 \\
\hline To decrease HIV transmission & 49 & 24.4 \\
\hline $\begin{array}{l}\text { To benefit sexual partner to get } \\
\text { medical care }\end{array}$ & 42 & 20.9 \\
\hline To adhere ARV drug regimen & 32 & 15.9 \\
\hline The presence of ARV drug at home & 14 & 7 \\
\hline Spiritual responsibility & 11 & 5.4 \\
\hline \multicolumn{3}{|l|}{ Reasons for non disclosure $(n=114)$} \\
\hline Fear of abandonment & 26 & 22.8 \\
\hline Fear of a shaming family & 9 & 7.9 \\
\hline Lack of communication skill & 9 & 7.9 \\
\hline Loss of confidentiality & 8 & 7 \\
\hline Fear of hurt & 14 & 12.3 \\
\hline Fear of accusation of infidelity & 10 & 8.8 \\
\hline Fear of stigma and discrimination & 14 & 12.3 \\
\hline Not enough time to discuss & 21 & 18.4 \\
\hline I do not want him to worry & 3 & 2.6 \\
\hline \multicolumn{3}{|l|}{ Time of intention for disclosure $(n=38)$} \\
\hline Within a week & 16 & 42.1 \\
\hline Within a month & 22 & 57.9 \\
\hline \multicolumn{3}{|l|}{$\begin{array}{l}\text { Have you had sex in the last } \\
6 \text { months }(n=315)\end{array}$} \\
\hline Yes & 174 & 55.2 \\
\hline No & 141 & 44.8 \\
\hline
\end{tabular}

Table 3 Sexual experiences and factors related to HIV disclosure among women at Mekelle Hospital, Northern Ethiopia (Continued)

Use condom $(n=174)$

$\begin{array}{lll}\text { Yes } & 116 & 66.7 \\ \text { No } & 58 & 33.3 \\ \text { Time of using condom }(n=116) & 75 & \\ \text { Always } & 41 & 35.6 \\ \text { Some times } & 41.6\end{array}$

and accusation of infidelity were the main reasons mentioned by the respondents for their non-disclosure. The finding of this study was similar to studies conducted in Mettu and Gore town, Kemissie health center and Hawassa University Referral Hospital $[5,12,13]$.

The presence of model person is important to increase people doing the action. In line to this, the study revealed that women who had seen somebody disclosing his/her HIV status to the community were more likely to disclose their HIV status to their partner. This was consistent with a finding of the review paper by the World Health Organization and a study done in Uganda [20,21].

Knowledge of partner's HIV status also determined the decision to disclose their HIV status to their partner and this is comparable with the finding of studies conducted in Kemissie Health Center, Hawassa referral hospitals, Jimma University specialized Hospital [12,13,15]. HIV positive status of their partner might have helped women to have open communication and freedom to disclose their status without any fear.

Sharing of one's own ideas with health providers and other clients could develop self confidence to describe their status to their partners and the community. One of the objectives of the counseling during HIV testing to psychologically help women, relief stress, anticipate the consequences and opportunity that could happen regardless of the test result. Hence, women who had pretest counseling had a higher proportion of disclosing their status to their partners. This is also consistent with other studies $[17,20]$.

This study showed that women who had prior discussions with their partner about HIV and HIV test were more likely to disclose their status than their counterpart. This finding corresponds with studies done in Gore and Metu, Kemissie Health Center and Jimma university specialized Hospital $[5,12,15]$. This might be due to the fact that, communicating with one's partner prior to HIV testing is a key point in individuals to anticipate a partner's reaction and would give them an opportunity to raise the issues and disclose their results.

Furthermore, this study revealed that women who considered initiation of ART is important for disclosure were more likely to disclose their HIV status than their 
Table 4 Predictors of HIV disclosure among women on ART at Mekelle Hospital, Northern Ethiopia

\begin{tabular}{|c|c|c|c|c|}
\hline \multirow[t]{3}{*}{ Characteristics } & \multicolumn{2}{|c|}{ Disclosure of HIV status } & \multirow[t]{3}{*}{ COR } & \multirow[t]{3}{*}{ AOR } \\
\hline & Yes & No & & \\
\hline & No (\%) & No (\%) & & \\
\hline \multicolumn{5}{|c|}{ Know partner HIV status } \\
\hline Yes & $139(92.7)$ & $11(7.3)$ & $20.9(10.52,41.85)$ & $16.9(8.11,35.21)^{*}$ \\
\hline No & $62(37.6)$ & $103(62.4)$ & 1 & 1 \\
\hline \multicolumn{5}{|c|}{ Since they know their status } \\
\hline$\leq 2$ years & $63(50.8)$ & $61(49.2)$ & 1 & 1 \\
\hline$>2$ years & $138(72.3)$ & $53(27.7)$ & $2.5(1.57,4.04)$ & $3.2(1.7,6.29)^{*}$ \\
\hline \multicolumn{5}{|c|}{ Got pretest counseling } \\
\hline Yes & $177(66.8)$ & $88(33.2)$ & $2.1(1.18,4.01))$ & $2.8(1.83,4.28)$ \\
\hline No & $24(48)$ & $26(52)$ & 1 & 1 \\
\hline \multicolumn{5}{|c|}{ Thinking that initiating ART important for disclosure } \\
\hline Yes & $171(67.6)$ & $82(32.4)$ & $2.2(1.26,3.9)$ & $1.7(0.81,3.54)$ \\
\hline No & $30(48.4)$ & $32(51.6)$ & 1 & 1 \\
\hline \multicolumn{5}{|c|}{ Have you had sex in the last 6 months } \\
\hline Yes & $131(75.3)$ & $43(24.7)$ & $3.1(1.91,4.93)$ & $3.2(1.7,6.19)^{*}$ \\
\hline No & $70(49.6)$ & $71(50.4)$ & 1 & 1 \\
\hline \multicolumn{5}{|c|}{$\begin{array}{l}\text { Seen a person with HIV positive disclose his/her } \\
\text { status to the community }\end{array}$} \\
\hline Yes & $111(75.5)$ & $36(24.5)$ & $2.6(1.64,4.33)$ & $2.1(1.08,4.01)^{*}$ \\
\hline No & $90(53.6)$ & $78(46.6)$ & 1 & 1 \\
\hline \multicolumn{5}{|c|}{ Women's treatment category } \\
\hline ART & $180(66.7)$ & $90(33.3)$ & 1 & 1 \\
\hline Pre ART & $21(46.7)$ & $24(53.3)$ & $0.4(0.23,0.82)$ & $0.6(0.24,1.61)$ \\
\hline \multicolumn{5}{|l|}{ Use condom } \\
\hline Yes & 97 (83.6) & $19(16.4)$ & $4.1(2.03,8.47)$ & $1.4(0.65,2.71)$ \\
\hline No & $32(55.2)$ & $26(44.8)$ & 1 & 1 \\
\hline \multicolumn{5}{|c|}{ Prior discussion before test } \\
\hline Yes & $86(86.9)$ & $13(13.1)$ & $5.81(3.068,11.04)$ & $4.87(2.45,9.71)^{*}$ \\
\hline No & $115(53.2)$ & $101(46.8)$ & 1 & 1 \\
\hline
\end{tabular}

*Significant at $p$ value $<0.05$.

complement. This finding was similar to the study done in Tanzania on PLWHA on assessing the impact of initiation of HAART, which showed that 59.5\% males and $48.7 \%$ females disclosed their HIV test result to a sexual partner after 12 months of initiation of HAART and in Mityana district of Uganda $[16,21]$. This could be explained by the fact that initially people on ART receive pre ART counseling, where disclosure is vital to the HIV/AIDS care and support. Secondly, ART was initiated by people who have already developed overt AIDS symptoms and signs that cannot easily be concealed from their partners.

Obtaining a continuous counseling at each contact with health providers and use of different behavior changing techniques might help for patients develop healthy behaviors, including disclosure of HIV sero positive status to sexual partners. Moreover, being women of developing countries in which most of the resources are in the palms of their husband, knowing their sexual partner status is crucial for disclosing their status freely. Different studies $[13,15]$ agree on the fact that women who knew their sexual partner's HIV status were more likely to disclose their HIV sero status than their counterparts.

It is obvious that a change in behavior is as a result of learning. Education is a vital to bring about behavioral change within a short period of time. Moreover, having a smooth relationship as well as sharing the same house could help for the women to express her feeling freely as well as makes them to get psychological and social support. However, unlike other studies, educational status, 
condom usage, having smooth relationships with their partners, living within the same house with their partner and being married were not significantly associated with HIV positive status disclosure. This variation may be attributable to the differences in the sample size and the design. The design computed the sample size based on the proportion of women with respect to HIV disclosure; it didn't consider the proportion of women needed based on the independent factors such as education.

\section{Conclusion}

The proportion of HIV status disclosure is low. Knowledge of HIV status of partner, receiving pretest counseling, longer time for the HIV testing, know people who disclose their status to the community and having discussion prior to HIV testing could influence disclosure of HIV status of mothers to their partners.

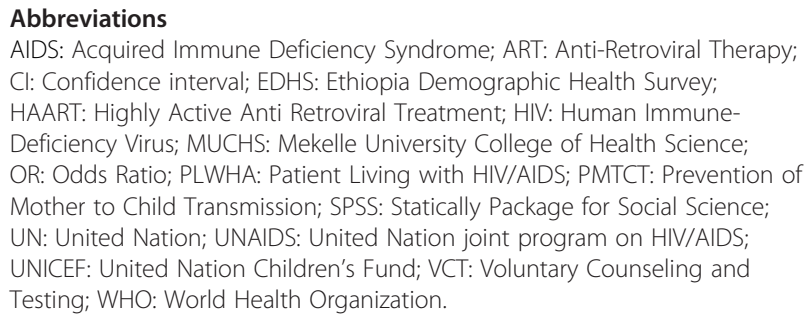

\section{Competing interests}

The authors declare that they have no competing interests.

\section{Authors' contributions}

$M A, A A, A K$ and $H Y$ : initiation of the study, design, implementation, analysis and writing and discussion. All authors read and approved the final manuscript and have equal contribution.

\section{Acknowledgement}

The authors are grateful for Mekelle University, College of Health Sciences for facilitating the study and Sheba University College for funding the project. Also, we would like to thank the staff of ART clinics at Mekelle hospital, data collectors and supervisors for their unreserved contribution to the success of the research. We would like to thank to Dr. Alemayaehu Byray for editing of the manuscript.

\section{Author details}

'Department of Public Health, Mekelle University College of Health Sciences, Mekelle, Ethiopia. ${ }^{2}$ Department of Nursing, Mekelle University College of Health Sciences, Mekelle, Ethiopia. ${ }^{3}$ Department of Nursing, Sheba University College, Mekelle, Ethiopia.

Received: 31 December 2013 Accepted: 17 July 2014

Published: 23 July 2014

\section{References}

1. Margaret C, Michel S, Anthony L: HIV/AIDS response - epidemic update and health sector progress towards universal access - progress report. World Health Organization: UNAIDS.UNICEF; 2011.

2. Michel S: UNAIDS report on the global AIDS epidemic, The global reference books on the AIDS epidemic and response. Geneva, Swizerland: UNAIDS; 2010.

3. FHAPCO: Report on progress towards implementation of the UN Declaration of Commitment on HIV/AIDS. Addis Ababa: FMOH; 2010.

4. Medley A, Garcia-Moreno CC, MC Gill S, Maman S: Rates, barriers and outcomes of HIV sero status disclosure among women in developing countries; Implications for prevention of mother-to-child transmission programs. Bull World Health Organ 2004, 82:299-307.

5. Deribe KK, Lingerh W, Dejene Y: Determinants and outcomes of disclosing HIV-sero positive status to sexual partners among women in Mettu and Gore towns, Illubabor Zone southwest Ethiopia. Ethiopia J Health Dev 2005, 19(2):126-131.

6. UNAIDS,UNICEF,WFP,IUNDP, UNODC,UNESCO,WHO,WORLD BANK: Report on the Global AIDS Epidemic, 4th global report. Geneva,Swizerland: WHO Library Cataloguing-in-Publication Data; 2004.

7. Stirratt MJ, Remien RH, Smith A, Copeland OQ, Dolezal C, Krieger D: The role of HIV serostatus disclosure in antiretroviral medication adherence. AIDS Behav 2006, 10(5):483-93.

8. FMOH. National HIV/AIDS Counseling Training Manual: Ministry of health, disease prevention and control department. Addis Ababa, Ethiopia; 2003. Accessed on April, 2013 www.moh.gov.et.

9. Larkins S, Reback CJ, Shoptaw S, Veniegas R: Methamphetamine-dependent gay men's disclosure of their HIV status to sexual partners. AIDS Care 2005, 17:521-532 [PubMed].

10. Kalichman SC, Nachimson D: Self-efficacy and disclosure of HIV positive sero status to sex partners. Health Psychol 1999, 18:281-287.

11. Genessa G, Kripa K, MCI: Health needs assessment for Mekelle town, ETHIOPIA; 2009. Available at Website: http://www.earth.columbia.edu. Accessed on June 22,2012.

12. Mohammed S, Belaynew W, Mengesha A: Disclosure of HIV positive result to a sexual partner among adult clinical service users in Kemissie district, northeast Ethiopia. Afr J Reprod Health 2012, 16(1):97.

13. Taye G, Dereje H, Endrias M: HIV positive status disclosure to sexual partners among Women attending ART clinics at Hawassa University Referral Hospital, SNNPR, Ethiopia. Ethiop J Health Dev 2010, 24(1):9-14.

14. Dave SS, Stephenson J, Mercey ED, Panahmand N, Jungmann E: Sexual behavior, condom use, and disclosure of HIV status in HIV infected heterosexual individuals attending an inner London HIV clinic. Sex Transm Inf 2006, 82:117-119.

15. Kebede D, Kifle W, Mekitie W, Amaha H, Alemayehu A: Disclosure experience and associated factors among HIV positive men and women clinical service users in Southwest, Ethiopia. BMC Public Health 2008, 8:81.

16. Maman S, Mbwambo J, Hogan M, Kilonzo GP, Weiss E, Sweat M: High Rates and Positive Outcomes of HIV Serostatus Disclosure to Sexual Partners: Reasons for Cautious Optimism from a VCT Clinic in Dar es Salaam, Tanzania. AIDS Behav 2003, (4):373-382.

17. Van der Straten A, King R, Grinstead O, Serufilira A, Allen S: Couple communication, sexual coercion and HIV risk reduction in Kigali, Rwanda. AIDS 1995, 9:935-944. /57.

18. MacNeil JM, Mberesero F, Kilonzo G: Is care and support associated with preventive behavior among people with HIV? AIDS Care 1999, 11:537-546.

19. Antelman G, Smith Fawzi MC, Kaaya S, Mbwambo J, Msamanga Gl, Hunter DJ, Fawzi WW: Predictors of HIV-1 status disclosure: a prospective study among HIV-infected pregnant women in Daresalaam, Tanzania. Aids 2001, 15:1865-1874.

20. World Health Organization: Gender dimensions of HIV status discourse to sexual partners. Rates, barriers \& outcomes: a review paper. Geneva, Switzerland: WHO; 2004.

21. Kilewo C, Massawe A, Lyamuya E, Semali I, Kalokola F, Urassa E, Giattas M, Temu F, Karlsson K, Mhalu F, Biberfeld G: HIV counseling and testing of pregnant women in Sub-Saharan Africa. J Acquir Immune Defic Syndr 2001, 28:458-462.

doi:10.1186/1471-2458-14-746

Cite this article as: Alemayehu et al.: HIV disclosure to sexual partner and associated factors among women attending ART clinic at Mekelle hospital, Northern Ethiopia. BMC Public Health 2014 14:746. 